\title{
MJMR PERCEPTIONS OF UNDERGRADUATE DENTAL STUDENTS AND GRADUATE DENTISTS TOWARDS BEHAVIOURAL GUIDANCE TECHNIQUES IN PAEDIATRIC DENTISTRY: A CROSS-SECTIONAL STUDY
}

\author{
Yy Jean Tan ${ }^{1 *}$, Kee Khing Teo², Hooi Si Teoh³, Then Lung Tong ${ }^{4}$, Shilpa Prabhakar \\ Hiremath $^{5}$ \\ ${ }^{1}$ Department of Oral and Maxillofacial Surgery, Dental Specialist Clinic, Sarawak General Hospital, \\ Jalan Tun Ahmad Zaidi Adruce, 93586, Kuching, Sarawak, Malaysia \\ ${ }^{2}$ Primecare Dental Serdang, 45-2, Jalan BS 4/1, Taman Bukit Serdang, 43300, Seri Kembangan, \\ Selangor, Malaysia \\ ${ }^{3}$ Tiew Dental Clinic, 2A, Jalan Kenari 1, Bandar Puchong Jaya, 47100, Puchong, Selangor, Malaysia \\ ${ }^{4}$ TAC dental Clinic, 5, 1 st Floor, Jalan Tembikai, Taman Suria, 86000, Kluang, Johor, Malaysia \\ ${ }^{5}$ Department of Paediatric Dentistry, Faculty of Dentistry, Asian Institute of Medicine, Science and \\ Technology (AIMST) University, 08100, Bedong, Kedah, Malaysia \\ *Corresponding Author’s E-mail: yyjeantan@gmail.com
}

\begin{abstract}
Objectives: This study aimed to evaluate perceptions of undergraduate dental students and graduate dentists towards behavioural guidance techniques in paediatric dentistry. Materials \& Methods: 225 subjects with previous experience in treating paediatric patient were identified and invited to fill up a Likert-style questionnaire with 15 questions in total. The data was evaluated for descriptive analysis and statistical analysis using Pearson's chi-square test and Fisher's exact test (significance level, $p<0.05$ ). Results: 158 respondents with mean age of 23.92 were included in this study. 75 respondents (47.4\%) think that communication is the most effective non-pharmacological method of behavioural guidance. 99 respondents $(62.6 \%)$ think that tell-show-do is the most practical behaviour shaping techniques. 69 respondents $(43.7 \%)$ are neutral to use HOME or physical restraints. 141 respondents $(89.2 \%)$ had used euphemism on the child patients. 125 respondents $(79.1 \%)$ had never used protective stabilization method. 64 respondents $(40.5 \%)$ think that their child patients some times struggled when receiving their treatment. The period of practicing in paediatric dentistry was significantly associated with the preference of most effective non-pharmacological method of behavioural guidance, the most practical behaviour shaping techniques, perceptions of using HOME or physical restraints, experience of using euphemism and the frequency of their child patients struggling when receiving dental treatment. The age of respondents was significantly associated with the use protective stabilization method. Conclusion: Generally, the respondents demonstrated satisfactory knowledge and acceptance of various behavioural guidance techniques in paediatric dentistry, but with some deficiencies.
\end{abstract}

\section{Keywords: Paediatric Dentistry, Behavioural Guidance, Dental Education}

\section{INTRODUCTION}

Managing children's behaviour during dental treatment is an important aspect of paediatric dentistry (Roberts et al., 2010). Children's behaviour management is vital in paediatric dental practice since a considerable number of children refuse to comply during dental treatment, posing a barrier to providing high-quality dental care (Paryab et al., 2014). It is as fundamental to the successful treatment of children along with skills and knowledge of dental materials in dental practice (Pinkham, 1990). A positive change in the children's behaviour is achieved through the application of various behavioural guidance $(\mathrm{BG})$ techniques (Kawia etal., 2015).
BG techniques aimed at improving a child's coping abilities, gaining full acceptance and the willingness of dental care, and reducing the child's perception that the dental treatment is overwhelming or terrifying (Roberts et al., 2010). In other words, when attending a child patient, dental practitioners utilize these techniques in order to establish communication, reduce fear and anxiety, promote the delivery of quality dental care, build a trusting relationship between the dentist, the child, and the parent, and cultivate the child's positive attitude toward dental treatment, increasing the child's ability to cope with and their willingness to undergo dental treatment (American Academy of Pediatric Dentistry, 2020; Crossley \& Joshi, 2002; Oliver \& Manton, 2015). 
Undergraduate dental students can learn and practice their first behaviour management strategies in the university clinic. The faculty has numerous opportunities to demonstrate behavioural guidance techniques that may potentially have an long-term impact on students and their practice (York et al., 2007). In order to have a successful paediatric dental treatment, appropriate strategies must be chosen, which are based on procedures that encourage children's cooperative behaviour and knowledge gained during formal dental training (Batista et al., 2011). The student's self-confidence in dealing with those uncooperative patient varied according to the extent of the child's reaction and the invasiveness of the procedure (Batista et al., 2011). Competence in anxiety-reducing techniques is associated with selfefficacy and the site of education (Brahm et al., 2013). Dental students at the beginning of their dental education course have had little to no exposure to BG techniques, so their perspective can be compared to a degree to that of parents and children. Nonetheless, as they receive the didactics' method of teaching about BG techniques and begin to treat children, their perspective may be influenced by the educational process (Sotto et al., 2008).

With the exception of hand over mouth exercise (HOME), the majority of pre-doctoral paediatric dentistry programmes teach communicative and pharmacologic behaviour management techniques as acceptable techniques. Most dental students receive some clinical experience with all communicative techniques. Dental students receive less clinical experience with pharmacologic techniques (Adair et al., 2004).Generally, children judged a BG technique based on how it appeared; hence, the least acceptable $\mathrm{BG}$ technique was hand over mouth exercise (HOME), whereas the most acceptable BG technique wastellshow-do (TSD) (Kantaputra et al., 2007).

Clinical guidelines on behavioural guidance for paediatric dental patients was developed by the American Academy of Paediatric Dentistry (AAPD) to help dentists and dental students working with the child patients. The guidelines divided BG techniques into basic and advanced behavioural guidance techniques, as well as indications for their respective uses. All these techniques are routinely practiced in paediatric dental practice with certain contraindication in certain scenario (Oueis et al., 2010).

Based on the above guidelines, a questionnaire-based survey was designed for undergraduate dental students and graduate dentists from AIMST University, Malaysia. The aim of the present study was to evaluate the perceptions of undergraduate dental students and graduate dentists towards BG techniques in paediatric dentistry in Malaysia.

\section{METHODOLOGY}

This descriptive, cross-sectional questionnaire-based study was carried out between 2016 and 2017 at the Faculty of Dentistry, AIMST University, Malaysia, after receiving the approval from the AIMST University Human and Animal Ethics Committee (AUHAEC/FOD/2016/22). 225 subjects from 3 batches of individuals consisting of undergraduate dental students and immediate graduates from AIMST University with previous experience in treating paediatric patient were identified. Given a targeted population size of 225 , a margin of error $5.0 \%$, a confidence interval of $95 \%$, and a response rate of $50 \%$ for those individuals who had the experience of direct care with child patient, a minimum of 143 subjects was required to produce a statistically accurate result. Those who are able to understand, communicate fully cooperate and willing to provide their consent were included in this study. Informed consent was obtained from each respondent following a thorough explanation of the purpose and contents of research. Exclusion criteria are those who don't have clinical experience in treating paediatric patients and those who aren't graduates from AIMST University.

Demographic data (age, gender and the period of practicing in paediatric dentistry) of the respondents were collected using a self-constructed questionnaire. This questionnaire was developed based on the objective of the study and face validated by a dental public health specialist, a paediatric dentist and four undergraduate dental students. Eligible subjects are invited to fill up a Likert-style questionnaire with 15 questions in total. The questions were based on BG techniques and knowledge of the same. In each question, multiple options will be given and is recorded in the form of a table in numerical number according to the sequence of the option. All the questions were on Google Docs and is emailed to volunteer individuals. Each person can answer the questionnaire once only, thus no repetition is recorded.

The data was entered into a Microsoft Excel (Microsoft Corp., Redmond, WA) spreadsheet and was evaluated for descriptive analysis (frequency and percentage). Statistical calculation was done using Chi-square test and Fisher's exact test to assess the association between different aspect in BG techniques and respondents' variables, namely age, gender and period of practising in paediatric dentistry. A significance level of 0.05 was 
adopted. Data analyses were conducted using SPSS version 22.0 software package (SPSS Inc, Chicago, IL, USA).

\section{RESULT}

Of 225 subjects, 158 respondents completed the questionnaire and were included in this study (Table 1). Their ages ranged from 21 to 28 , with mean age of 23.92 . $38.6 \%$ of respondents are age between 23-24 years old. Most of the respondents are of Year 5 dental students and immediate graduates of Bachelor of Dental Surgery. Majority of the respondents are female, occupied $62.7 \%$ $(n=99)$ of the total percentage, whereas $37.3 \%(n=59)$ are male. Majority of the respondents have been practicing paediatric dentistry for $0-6$ months, occupied $48.1 \%$ of the total percentage. paediatric dentistry for $0-6$ months, occupied $48.1 \%$ of the total percentage.

\section{Table 1: Demographic Data of the Respondents}

\begin{tabular}{|l|c|c|}
\hline \multicolumn{1}{|c|}{ Variable } & Frequency(n) & Percentage(\%) \\
\hline Age Group & & \\
\hline$<25$ & 128 & 81 \\
\hline$\geq 25$ & 30 & 19 \\
\hline Gender & & \\
\hline Male & 59 & 37.3 \\
\hline Female & 99 & 62.7 \\
\hline $\begin{array}{l}\text { Period of Practising in } \\
\text { Paediatric Dentistry }\end{array}$ & & \\
\hline 0 - 6 months & 76 & 48.1 \\
\hline 6-12 months & 52 & 32.9 \\
\hline$>12$ months & 30 & 19 \\
\hline
\end{tabular}

Table 2: Data Recorded in the Present Questionnaire Study

\begin{tabular}{|c|c|c|c|}
\hline Question & Options & Frequency(n) & Percentage (\%) \\
\hline \multirow{3}{*}{$\begin{array}{l}\text { 1. Which non-pharmacological } \\
\text { method of } \\
\text { behaviouralguidance is most } \\
\text { effective in controlling your } \\
\text { patient in dental set-up? }\end{array}$} & Communication & 75 & $47.40 \%$ \\
\hline & $\begin{array}{l}\text { Behaviour shaping } \\
\text { (modification) }\end{array}$ & 48 & $30.40 \%$ \\
\hline & Behaviour management & 35 & $22.20 \%$ \\
\hline \multirow{5}{*}{$\begin{array}{l}\text { 2. Among the behaviour } \\
\text { shaping techniques, which, in } \\
\text { your opinion is most practical? }\end{array}$} & Desensitization & 26 & $16.50 \%$ \\
\hline & Modelling & 29 & $18.40 \%$ \\
\hline & Contingency management & 4 & $2.50 \%$ \\
\hline & Tell-show-do & 99 & $62.60 \%$ \\
\hline & Any other (please specify) & 0 & $0 \%$ \\
\hline \multirow{4}{*}{$\begin{array}{l}\text { 3. What kind of cries based on } \\
\text { Elsbach } 1963 \text { do your patients } \\
\text { show most often? }\end{array}$} & Obstinate cry & 25 & $15.80 \%$ \\
\hline & Frightened cry & 89 & $56.35 \%$ \\
\hline & Hurt cry & 15 & $9.50 \%$ \\
\hline & Compensatory cry & 29 & $18.40 \%$ \\
\hline \multirow{5}{*}{$\begin{array}{l}\text { 4. Have you ever used HOME } \\
\text { or physical restraint before? }\end{array}$} & Strongly Agree & 4 & $2.50 \%$ \\
\hline & Agree & 25 & $15.80 \%$ \\
\hline & Neutral & 69 & $43.70 \%$ \\
\hline & Disagree & 32 & $20.30 \%$ \\
\hline & Strongly Disagree & 28 & $17.70 \%$ \\
\hline \multirow{2}{*}{$\begin{array}{l}\text { 5. Have you ever explained } \\
\text { what is going on during the } \\
\text { dental treatment to the child? }\end{array}$} & Yes & 138 & $87.30 \%$ \\
\hline & No & 20 & $12.70 \%$ \\
\hline \multirow{2}{*}{$\begin{array}{l}\text { 6. Have you ever used } \\
\text { euphemisms (an expression } \\
\text { intended to be less offensive } \\
\text { than the word it replaces) to } \\
\text { describe dental procedures? }\end{array}$} & Yes & 141 & $89.20 \%$ \\
\hline & No & 17 & $10.80 \%$ \\
\hline
\end{tabular}




\begin{tabular}{|c|c|c|c|}
\hline \multirow{2}{*}{$\begin{array}{l}\text { 7. Do you prefer the absence or } \\
\text { presence of the child's parents } \\
\text { by their side during treatment? }\end{array}$} & Yes & 64 & $59.50 \%$ \\
\hline & No & 94 & $40.50 \%$ \\
\hline \multirow{2}{*}{$\begin{array}{l}\text { 8. Have you ever restrict a } \\
\text { child's movement with the } \\
\text { dental staff, and/or a parent? Is } \\
\text { he/she held firmly in place? }\end{array}$} & Yes & 33 & $20.90 \%$ \\
\hline & No & 125 & $79.10 \%$ \\
\hline \multirow{2}{*}{$\begin{array}{l}\text { 9. In your opinion, do you feel } \\
\text { or think that the dental set-up } \\
\text { that you are working at is } \\
\text { favourable and conducive for } \\
\text { the paediatric patients? }\end{array}$} & Yes & 120 & $75.90 \%$ \\
\hline & No & 38 & $24.10 \%$ \\
\hline \multirow{5}{*}{$\begin{array}{l}10 . \text { How often does your } \\
\text { paediatric patient struggle } \\
\text { when receiving their } \\
\text { treatment? }\end{array}$} & Almost never & 29 & $18.40 \%$ \\
\hline & Once in a while & 54 & $34.20 \%$ \\
\hline & Sometimes & 64 & $40.50 \%$ \\
\hline & Frequently & 10 & $6.30 \%$ \\
\hline & Most of the time & 1 & $0.60 \%$ \\
\hline \multirow{5}{*}{$\begin{array}{l}\text { 11. How much effort do you } \\
\text { put into getting your paediatric } \\
\text { patient treated? }\end{array}$} & Almost no effort & 9 & $5.70 \%$ \\
\hline & A little bit of effort & 34 & $21.50 \%$ \\
\hline & Some effort & 53 & $33.50 \%$ \\
\hline & Quite a bit of effort & 48 & $30.40 \%$ \\
\hline & $\begin{array}{c}\text { A tremendous amount of } \\
\text { effort }\end{array}$ & 14 & $8.90 \%$ \\
\hline \multirow{13}{*}{$\begin{array}{l}\text { 12. According to you, which is } \\
\text { the most effective method to } \\
\text { reduce dental fear and anxiety } \\
\text { in child patient? }\end{array}$} & Use of euphemisms & 18 & $11.40 \%$ \\
\hline & Reframing & 0 & $0 \%$ \\
\hline & Desensitization & 62 & $39.20 \%$ \\
\hline & Modelling & 30 & $19 \%$ \\
\hline & Contingency management & 3 & $1.90 \%$ \\
\hline & Audio analgesia & 1 & $0.60 \%$ \\
\hline & Biofeedback & 0 & $0 \%$ \\
\hline & Humour & 19 & $12 \%$ \\
\hline & Coping & 8 & $5.10 \%$ \\
\hline & Voice control & 3 & $1.90 \%$ \\
\hline & Relaxation & 12 & $7.60 \%$ \\
\hline & Hypnosis & 1 & $0.60 \%$ \\
\hline & Aversive conditioning & 1 & $0.60 \%$ \\
\hline \multirow{4}{*}{$\begin{array}{l}\text { 13. How regular do you use the } \\
\text { Hand Over Mouth (HOME) } \\
\text { Technique to control your } \\
\text { patients? }\end{array}$} & Almost never & 128 & $81 \%$ \\
\hline & Once in a while & 21 & $13.30 \%$ \\
\hline & Sometimes & 7 & $4.40 \%$ \\
\hline & Frequently & 2 & $1.30 \%$ \\
\hline
\end{tabular}




\begin{tabular}{|c|c|c|c|}
\hline \multirow{13}{*}{$\begin{array}{l}\text { 14. Of the methods been } \\
\text { already used in patient } \\
\text { behaviour modification } \\
\text { techniques, which, according } \\
\text { to you have proven to be } \\
\text { successful? }\end{array}$} & Tell-show-do & 72 & $45.60 \%$ \\
\hline & Euphemism & 7 & $4.40 \%$ \\
\hline & Desensitization & 18 & $11.40 \%$ \\
\hline & Voice control & 11 & $7 \%$ \\
\hline & Modelling & 28 & $17.70 \%$ \\
\hline & Aversive conditioning & 1 & $0.60 \%$ \\
\hline & Audio analgesia & 1 & $0.60 \%$ \\
\hline & Communication & 10 & $6.30 \%$ \\
\hline & Humour & 4 & $2.50 \%$ \\
\hline & HOME & 1 & $0.60 \%$ \\
\hline & Coping & 2 & $1.30 \%$ \\
\hline & Contingency management & 2 & $1.30 \%$ \\
\hline & Tender love and care & 1 & $0.60 \%$ \\
\hline \multirow{2}{*}{$\begin{array}{l}\text { 15. Would you consider taking } \\
\text { paediatric dentistry as an } \\
\text { option for further studies after } \\
\text { graduation? }\end{array}$} & Yes & 42 & $26.60 \%$ \\
\hline & No & 116 & $73.40 \%$ \\
\hline
\end{tabular}

The survey results are displayed in Table 2 . Respondents ' preference of most effective BG techniques in controlling patient in dental set-up is communication technique $(47.4 \%)$. The period of practicing in paediatric dentistry was significantly associated with the preference of most effective nonpharmacological method of behavioural guidance in controlling patient in dental set-up $(p=0.028)$ (Table 3$)$.
In respondents ' preference of most practical behaviour shaping techniques, tell-show-do $(62.6 \%)$ is the most chosen option. The period of practicing in paediatric dentistry was significantly associated with the preference of most practical behaviour shaping techniques $(p=0.024)$ (Table 3$) .56 .3 \%$ of respondents thinks that frightened cry is the most often type of cries, based on Elsbach 1963, shown by the patient.

Table 3: Pearson's Chi Square Association Between Respondent's Independent Variables (Age, Gender, Period of Practicing in Paediatric Dentistry) and the Data Recorded in the Present Questionnaire Study

\begin{tabular}{|c|c|c|c|c|c|c|}
\hline \multirow{2}{*}{ Questions } & \multicolumn{2}{|c|}{ Age of Respondents } & \multicolumn{2}{|c|}{ Gender of Respondents } & \multicolumn{2}{|c|}{$\begin{array}{c}\text { Period of Practicing in Paediatric } \\
\text { Dentistry }\end{array}$} \\
\hline & $\begin{array}{l}\text { Pearson's } \\
\text { chi-square }\end{array}$ & $p$ value & $\begin{array}{l}\text { Pearson's } \\
\text { chi-square }\end{array}$ & $p$ value & $\begin{array}{l}\text { Pearson's } \\
\text { chi-square }\end{array}$ & $p$ value \\
\hline Q1 & 0.940 & $\mathrm{p}=0.625$ & 2.633 & $\mathrm{p}=0.268$ & 10.913 & $\mathrm{p}=0.028^{*}$ \\
\hline Q2 & 3.012 & $\mathrm{p}=0.390$ & 3.287 & $\mathrm{p}=0.349$ & 14.059 & $\mathrm{p}=0.029 *$ \\
\hline Q3 & 2.141 & $\mathrm{p}=0.544$ & 1.741 & $\mathrm{p}=0.628$ & 8.890 & $\mathrm{p}=0.180$ \\
\hline Q4 & 5.313 & $\mathrm{p}=0.257$ & 8.088 & $\mathrm{p}=0.088$ & 19.223 & $\mathrm{p}=0.014^{*}$ \\
\hline Q5 & 1.202 & $\mathrm{p}_{\#}=0.370$ & 0.528 & $\mathrm{p}=0.468$ & 1.603 & $\mathrm{p}=0.449$ \\
\hline Q6 & 0.255 & $\mathrm{p}_{\#}=0.743$ & 1.981 & $\mathrm{p}=0.159$ & 10.934 & $\mathrm{p}=0.004^{*}$ \\
\hline Q7 & 0.791 & $\mathrm{p}=0.374$ & 0.405 & $\mathrm{p}=0.525$ & 4.067 & $\mathrm{p}=0.131$ \\
\hline Q8 & 11.292 & $\mathrm{p}=0.001 *$ & 0.883 & $\mathrm{p}=0.347$ & 5.582 & $\mathrm{p}=0.061$ \\
\hline Q9 & 0.010 & $\mathrm{p}=0.919$ & 1.507 & $\mathrm{p}=0.220$ & 1.816 & $\mathrm{p}=0.403$ \\
\hline Q10 & 7.894 & $\mathrm{p}=0.096$ & 3.024 & $\mathrm{p}=0.554$ & 24.132 & $\mathrm{p}=0.002 *$ \\
\hline Q11 & 3.763 & $\mathrm{p}=0.439$ & 4.431 & $\mathrm{p}=0.351$ & 12.018 & $\mathrm{p}=0.150$ \\
\hline
\end{tabular}


PERCEPTIONS OF DENTAL STUDENTS TOWARDS BEHAVIOURAL GUIDANCE MI $\underline{M}$

\begin{tabular}{|c|c|c|c|c|c|c|}
\hline $\mathrm{Q} 12$ & 3.308 & $\mathrm{p}=0.973$ & 9.321 & $\mathrm{p}=0.502$ & 24.545 & $\mathrm{p}=0.219$ \\
\hline $\mathrm{Q} 13$ & 3.649 & $\mathrm{p}=0.302$ & 3.732 & $\mathrm{p}=0.292$ & 7.841 & $\mathrm{p}=0.250$ \\
\hline $\mathrm{Q} 14$ & 10.835 & $\mathrm{p}=0.543$ & 15.662 & $\mathrm{p}=0.207$ & 29.503 & $\mathrm{p}=0.202$ \\
\hline $\mathrm{Q} 15$ & 0.822 & $\mathrm{p}=0.365$ & 4.477 & $\mathrm{p}=0.034^{*}$ & 3.383 & $\mathrm{p}=0.184$ \\
\hline
\end{tabular}

*Statistically significant at $p<0.05$; \#: Fisher's Exact Test

Most of the respondents (43.7\%) are neutral to use HOME or physical restraints as BG technique and in controlling paediatric patient in dental set-up. The period of practicing in paediatric dentistry was significantly associated with the respondents' neutral view on the use of HOME or physical restraints as BG technique and in controlling paediatric patient in dental set-up ( $p=0.008)$ (Table 3 ). Most of the respondents $(87.3 \%)$ had explained procedures of dental treatment to the child to make them comfortable.

$89.2 \%$ of respondents had used euphemisms as BG technique on the child throughout dental treatment. The period of practicing in paediatric dentistry was significantly associated with the use of euphemisms on the child throughout dental treatment $(p=0.004)$ (Table 3 ). $59.5 \%$ of respondents agreed that the presence of the child's parent by their side can help in deliver dental treatment to the child more effectively.

$79.1 \%$ of the respondents agreed that immobilizing the paediatric patient is an effective BG technique and have ever immobilized a child with the help of dental staff, and/or a parent and he/she is held firmly in place. The age of respondents was significantly associated with the use protective stabilization method on the paediatric patient as an effective method $(p=0.001)$ (Table 3). $75.9 \%$ of the respondents feel or think that the dental set-up that they are working at is favourable and conducive for paediatric patients.

$40.5 \%$ of the respondents encountered sometimes their paediatric patients struggled when receiving their treatment. The period of practicing in paediatric dentistry was significantly associated with the struggling of paediatric patient when receiving their treatment $(p=0.002)$ (Table 3$)$.

$39.2 \%$ of the respondents think that desensitization is the most effective method to reduce dental fear and anxiety in child patient. An astounding $81.0 \%$ of the respondents almost never used the HOME method to control their paediatric patient.

Among 158 respondents, $45.6 \%$ answered tell-showdo as the most successful patient behaviour modification technique. $73.4 \%$ of them do not want to take paediatric dentistry as a postgraduate course in paediatric dentistry as an option for further studies after graduation. The gender of respondents was significantly associated with the respondents' consideration of taking paediatric dentistry as an option for further studies after graduation $(p=0.034)$ (Table 3).

\section{DISCUSSION}

Numerous peer-reviewed articles have clearly demonstrated that dental students can provide valuable and useful perspectives on their education (Bimstein $e t$ al., 2009). The current study showed that the respondents believe that communication is the most effective non-pharmacological method to control their patients in the dental set-up. These findings are consistent with the study by Grewal who reported that the majority of the respondents used communication technique when dealing with child patient (Grewal, 2003). Initiating conversation with the child patient at the beginning of dental appointment and being an active or reflective listener helps to establish rapport and trust with the patient.

In the present study, we concluded that that tell-showdo is the most practical and successful method in patient behaviour modification technique and the least popular methods are aversive conditioning, audio analgesia and tender love and care. In previous studies, Sharath et al., Adair et al. and Sotto et al. have suggested that TSD is considered as the important treatment plan for the child in their study (Adair et al., 2004; Sharath et al., 2009; Sotto et al., 2008).

We had found that most of the respondents had used euphemisms on the child throughout dental treatment. Euphemism is an expression which intended to be less offensive. Therefore, the use of euphemism or reframing is very important while addressing to the patient. When the child reaches the age range of 2-7 years, they begin addressing the objects symbolically. They correlate things with other objects which they are accustomed to such as toys and games. Thus, "Euphemism" can be considered as an effective tool (Rana et al., 2020). 
In the present study, most of the respondents agreed that the presence of the child's parent by their side can help in deliver dental treatment to the child more effectively. The presence of the parent helps in the child patient's cooperation for dental treatment as they offer them physical and psychological support. This is also important for the practitioners to catch the patient's attention and increase compliance, minimize anxiety and achieve a positive dental experience and facilitate rapid informed consent for changes in treatment or behavioural guidance. Our findings are consistent with study conducted by Shroff et al. in 2015 , in which they concluded that majority of respondents prefer the parents to be present in the dental operatory during the treatment (Shroff et al., 2015). 'However, Enrique Bimstein et al (Bimstein et al., 2009) reported low acceptability scores for the parent's presence in the clinic and talking with the child or the dentist/assistant during treatment.

Majority of the respondents in this study had never use protective stabilization on a child patient with the help of dental staff, and/or a parent during dental treatment. This is most probably due to lack of confidence in the respondents in using protective stabilization technique as they are new and inexperience in handling the child patient. This result is in contrast with the finding of previous study done by Sotto et al. (Sotto et al., 2008), which showed the increase in acceptability of passive and active protective stabilization by the respondents.

Adair et al (Adair et al., 2004) found that the majority of pre-doctoral programs believe that HOME is a technique not suited for general dentists without training and experience beyond dental school. However, in the present study, most of the respondents are neutral to use this technique as BG technique. This is most probably due to lack of understanding and usage of this technique by the respondents while treating child patient. Result from the present study also indicated that most of them almost never used HOME technique before whereas a few of them used the method frequently. Majority of the respondents are green horns as they have very little experience and exposure in the practice of paediatric dentistry. This could mean that their knowledge in paediatric dentistry is limited. Avoidance of usage of HOMEis most probably due to its removal from AAPD guidelines (Oueis et al., 2010).

Irrespective of the severity of the fear, dental treatment maybe challenging, not only for the patients but also for the caregivers. In order to reduce patient-related stress associated with the treatment of patients with dental fear, some anxiety-management techniques have been described. Brahm C.O. et al (Brahm et al., 2013) found that the most commonly used nonpharmacological behaviour management techniques is tell-show-do (86\%). In contrast, in the present study, the most popular method in reducing dental fear and anxiety in the child patient is desensitization and the least popular methods are reframing and biofeedback. Majority of the respondents think that desensitization is the most effective method to reduce dental fear and anxiety in child patient.

In our study, according to types of cries based on Elsbach 1963 (Elsbach, 1964), frightened cry shown most often by the patient, followed by compensatory cry, obstinate cry and the least often kind of cries shown is hurt cry. Elsbach reported 4 different types of cries and concluded that the type of cry is the key to understanding the behaviour pattern of the paediatric patient.

To be successful in paediatric dental treatment, it is necessary to choose adequate strategies, based on procedures that stimulate children's cooperative behaviour, knowledge which should have been acquired during formal dentistry training (Roberts et al., 2010). In our study, majority of the respondents had put some effort into getting their paediatric patient treated. This may be due to inadequate knowledge on BG technique on the child patient who is unwilling to cooperate or fear of dental personnel or instruments.

Last but not least, despite paediatric dentistry being an interesting branch of dentistry and allowing dentists to treat younger patients, majority of the respondents chose not to continue their studies in this field. This could be due to the branch being very challenging and arduous to handle. This is true especially when dealing with uncooperative and difficult children.

The limitation of the current study is that the samples obtained are from a single site (AIMST University). Further studies need to be done to assess the attitude of individuals of different universities towards the perceptions of BG techniques in paediatric dentistry due to different curricula in other dental school over the nation. It is also possible that some respondents do not completely understood the operational definitions of various BG techniques listedin the questionnaire.

\section{CONCLUSION}

Generally, the respondents demonstrated satisfactory 
knowledge and acceptance of various BG techniques in paediatric dentistry, but with some deficiencies. There is a need for more $\mathrm{BG}$ technique curriculum in the undergraduate dental curricula to meet the knowledge gaps in different basic and advanced BG techniques in order to handle uncooperative and difficult children effectively and safely. Dental students should be encouraged and educated using unique techniques to make paediatric dentistry a less threatening subject and children a less intimidating dental patient.

\section{Conflict of Interest}

No conflicts of interest related to this study.

\section{ACKNOWLEDGEMENT}

The authors would like to thank all the respondents of this study for their cooperation and support.

\section{FUNDING STATEMENT}

This study was self-funded by all authors.

\section{REFERENCES}

Adair, S. M., Schafer, T. E., Rockman, R. A., \& Waller, J. L. (2004). Survey of Behavior Management Teaching in Predoctoral Pediatric Dentistry Programs. Pediatric Dentistry, 26(2), 143-150.

American Academy of Pediatric Dentistry. (2020). Behavior Guidance for the Pediatric Dental Patient. The Reference Manual of Pediatric Dentistry, 292310.

Batista, C. G., Nascimento, C. L., Rolim, G. S., Rocha, R. A., Rodrigues, A. F., Ambrosano, G. M., \& Moraes, A. B. (2011). Student Self-confidence in Coping with Uncooperative Behaviours in Paediatric Dentistry. European Journal of Dental Education, 15(4), 199-204.

Bimstein, E., Azari, A. F., Sotto, J. J., \& Riley, J. L. (2009). Students' Perceptions About Pediatric Dental Behavior Guidance in an Undergraduate Four-year Dental Curriculum. Journal of Dental Education, 73(12), 1366-1371.

Brahm, C. O., Lundgren, J., Carlsson, S. G., Nilsson, P., Hultqvist, J., \& Hägglin, C. (2013). Dentists' Skills with Fearful Patients: Education and Treatment. European Journal of Oral Sciences, 121(3 Pt 2), 283-291.
Crossley, M. L., \& Joshi, G. (2002). An Investigation of Paediatric Dentists' Attitudes Towards Parental Accompaniment and Behavioural Management Techniques in the UK. British Dental Journal, 192(9), 517-521.

Elsbach, H. G. (1964). Crying as a Diagnostic Tool. Journal of the Institute of Health Education, 2(3), 19-21.

Grewal, N. (2003). Implementation of Behaviour Management Techniques-How Well Accepted They Are Today. Journal of the Indian Society of Pedodontics and Preventive Dentistry, 21(2), 7074.

Kantaputra, P. N., Chiewcharnvalijkit, K., Wairatpanich, K., Malikaew, P., \& Aramrattana, A. (2007). Children's Attitudes Toward Behavior Management Techniques Used by Dentists. Journal of Dentistry for Children 74(1), 4-9.

Kawia, H. M., Mbawalla, H. S., \& Kahabuka, F. K. (2015). Application of Behavior Management Techniques for Paediatric Dental Patients by Tanzanian Dental Practitioners. Open Dentistry Journal, 9, 455-461.

Oliver, K., \& Manton, D. J. (2015). Contemporary Behavior Management Techniques in Clinical Pediatric Dentistry: Out with the Old and In with the New? Journal of Dentistry for Children 82(1), $22-28$.

Oueis, H. S., Ralstrom, E., Miriyala, V., Molinari, G. E., \& Casamassimo, P. (2010). Alternatives for Hand Over Mouth Exercise After Its Elimination from the Clinical Guidelines of the American Academy of Pediatric Dentistry. Pediatric Dentistry, 32(3), 223228.

Paryab, M., Afshar, H., \& Mohammadi, R. (2014). Informing Parents About the Pharmacological and Invasive Behavior Management Techniques Used in Pediatric Dentistry. Journal of Dental Research, Dental Clinics, Dental Prospects, 8(2), 95-100.

Pinkham, J. R. (1990). Behavioral Themes in Dentistry for Children: 1968-1990. ASDC Journal of Dentistry for Children, 57(1), 38-45.

Rana, K., Saha, S., \& Sarkar, S. (2020). Dentist's Skills of Behavior Management: A Study of Knowledge, Attitude, and Practice of Dentists in Managing Child Patient. International Journal of Pedodontic 
Rehabilitation, 5(2), 44-48.

Roberts, J. F., Curzon, M. E., Koch, G., \& Martens, L. C. (2010). Review: Behaviour Management Techniques in Paediatric Dentistry. European Archives of Paediatric Dentistry, 11(4), 166-174.

Sharath, A., Rekka, P., Muthu, M. S., Rathna Prabhu, V., \& Sivakumar, N. (2009). Children's Behavior Pattern and Behavior Management Techniques Used in a Structured Postgraduate Dental Program. Journal of the Indian Society of Pedodontics and Preventive Dentistry, 27(1), 22-26.

Shroff, S., Hughes, C., \& Mobley, C. (2015). Attitudes and Preferences of Parents About Being Present in the Dental Operatory. Pediatric Dentistry, 37(1), 51-55.

Sotto, J. J., Azari, A. F., Riley, J., 3rd, \& Bimstein, E. (2008). First-year Students' Perceptions About Pediatric Dental Behavior Guidance Techniques: The Effect of Education. Journal of Dental Education, 72(9), 1029-1041.

York, K. M., Mlinac, M. E., Deibler, M. W., Creed, T. A., \& Ganem, I. (2007). Pediatric Behavior Management Techniques: A Survey of Predoctoral Dental Students. Journal of Dental Education, 71(4), 532-539. 